\title{
Comparative study of patient-based versus case-based teaching in prescription writing skills of second year MBBS students
}

\author{
Shilpa P. Jadav, Nishant B. Bhansali*, Dinesh M. Parmar
}

Department of Pharmacology, M.P. Shah Govt. Medical College, Jamnagar, Gujarat, India

Received: 21 November 2019

Revised: 07 January 2020

Accepted: 08 January 2020

*Correspondence:

Dr. Nishant B. Bhansali,

Email: dr.idreamz1785@gmail.com

Copyright: (C) the author(s), publisher and licensee Medip Academy. This is an open-access article distributed under the terms of the Creative Commons Attribution Non-Commercial License, which permits unrestricted non-commercial use, distribution, and reproduction in any medium, provided the original work is properly cited.

\begin{abstract}
Background: Prescription writing errors can lead to deficiencies in healthcare. Although prescription writing is a part of the medical students' curriculum with traditional methods, their prescribing skills are still poor due to inadequate training. To fulfil the need for new educational interventions this study aims to compare patient-based teaching with case-based teaching in improving prescription writing skills of second year MBBS students.

Methods: This prospective comparative study was carried out after orientation of participants to prescription writing as per WHO prescribing guidelines $(n=71)$. Group A $(n=37)$ and group B $(n=34)$ were given patient-based teaching and case-based teaching respectively of prescription writing for the same five common clinical conditions. The prescription writing skill was assessed by evaluating the prescriptions written by both the groups and scored by 19point scoring system. Feedback from the group A students was also taken.

Results: Statistical analysis of mean scores of group A (15.90) and group B (13.14) was done by Mann-Whitney U test $(p<0.001)$. Comparison of both the groups for the individual parameters was done by Chi-square test which found significant difference in writing some important parameters like doctor's registration no., contacts of prescriber, name of the medicine, strength of drug, dosage form, dosing instructions, total quantity of medicine and duration of medication etc. Group A students' feedback brought out the fact that patient-based teaching is a good tool for teaching and learning.

Conclusions: Patient-based teaching for prescription writing improves students' prescription writing skills in an effective way in comparison with traditional case-based teaching.
\end{abstract}

Keywords: Case-based teaching, Patient-based teaching, Prescription writing skills

\section{INTRODUCTION}

Prescription refers to a written order from health professional to a patient. It is one of the significant steps in patient management. The word prescription originates from Latin "pre" meaning before and "scribe" meaning writing. ${ }^{1}$ As we know medical students are future drug prescribers, they should be well aware with the all aspects of prescription writing. As such it is a complex task which require diagnostic skills, knowledge of drugs, communication skills, an understanding of the principles of clinical pharmacology etc. ${ }^{2}$ Common prescription writing errors like inappropriate prescription, irrational prescription, under prescribing, or over prescribing can lead to deficiencies in healthcare. ${ }^{3}$ Although prescription writing is a part of the medical students' curriculum, their prescribing skills are still poor either as a part of their examinations or as they go out as qualified health professionals. Although many prescribing errors are unintentional, studies have shown that the prescribing performance of interns and medical students are poor partly because of inadequate training. ${ }^{4}$ Studies also reveal 
that many medical graduates feel less-prepared to take on prescribing responsibilities after graduation even though prescription writing is taught by lectures or case-based teaching. ${ }^{5}$ Therefore, there is a need for new educational interventions to improve prescribing.

Patient-based teaching is one of the educational interventions to teach clinical skills using real patients which can offers lifelike preparation and has more relevance as a future doctor. This intervention may improve prescribing skills since the learning occurs within the context of real patients and is easier to recall. ${ }^{6}$

Based on the above facts, this study aimed to compare patient-based teaching with case-based teaching in prescription writing skills of second year MBBS students and to determine the role of educational intervention (patient-based teaching) to improve the prescribing skill of second year medical students.

\section{METHODS}

A prospective, comparative study conducted on all second year MBBS students who are willing to participate in the study $(n=71)$ of M.P. Shah Government Medical College and Guru Gobindsingh Government Hospital, Jamnagar from September 2017 to January 2018.

The project was started after taking permission from the Institution Ethics Committee and heads of the concerned departments. Informed consent of all the participants was taken. First, they were taught about prescription writing according to WHO guidelines, prescribing format and selection of the preferred drug after making clinical diagnosis. Then all students were divided randomly into two groups, A and B. Five common clinical conditions (malaria, diabetes mellitus, vomiting, ischemic heart disease and constipation) were selected (from present indoor patients in medicine department) for teaching prescription writing to both the groups.

The participants of the group A ( $n=37)$ were subjected to patient-based teaching which was carried out in the medicine department of a tertiary care teaching hospital. They were exposed to patients suffering from the selected clinical conditions. Students were given 15 min duration to interact with the patients; they were briefed about clinical conditions and appropriate prescriptions. After that they were asked to write prescriptions according to given information in groups and checked by teaching faculties for the errors, if any. Students of group B $(n=34)$ were trained on prescription writing by explaining five clinical conditions using case scenarios in the department of pharmacology. After allowing the participants of both the groups to undergo self-study for 2 days, they were asked to write prescriptions in the standard format for the same five clinical conditions discussed. Assessment of their prescribing skill is done by analyzing scores obtained. Scoring for the prescriptions written by all the participants is done by using preformed checklist (Table $1){ }^{7}$

The mean scores obtained by both the groups for the five prescriptions were analyzed using Mann-Whitney U test and the individual parameters in the 19-point score were compared by Chi-square test. Feedback was also obtained from the group A students with the help of pre-validated questionnaire. The questionnaire had two types of questions. First questions with a 5-point Likert scale (1=strongly disagree, 2=disagree, 3=neutral, 4=agree, $5=$ strongly agree) to assess their learning experience, perception towards the activity and level of satisfaction and second open-ended questions directed at their opinions, suggestions or comments with regard to the use of patient-based teaching. Average score and satisfaction index of each item was counted for Likert scale. For open ended questions common opinion was derived. The satisfaction index for each item was calculated using the following formula: ${ }^{8}$

$$
\frac{(n 1 \times 1)+(n 2 \times 2)+(n 4 \times 4)+(n 5 \times 5)] \times 20}{(n 1+n 2+n 4+n 5)}
$$

Where, $\mathrm{n}$ is the total number of students gaining the score mentioned in the subscript for that particular item. The scores were rated on a 1-100 satisfaction index scale. It was highest (94.85) for item 4 and lowest (85.71) for item 3.

Table 1: Prescription scoring checklist.

\begin{tabular}{|ll|}
\hline S. no. & Particulars \\
\hline $\mathbf{1}$ & Doctor's full name \\
\hline $\mathbf{2}$ & Doctor's qualifications \\
\hline $\mathbf{3}$ & Registration no. \\
\hline $\mathbf{4}$ & Address of doctor \\
\hline $\mathbf{5}$ & Contacts (of prescriber) \\
\hline $\mathbf{6}$ & Date of prescription \\
\hline $\mathbf{8}$ & Patient's full name \\
\hline $\mathbf{9}$ & Patient's full address \\
\hline $\mathbf{1 0}$ & Patient's sex \\
\hline $\mathbf{1 1}$ & Patient's age \\
\hline $\mathbf{1 2}$ & Patient's weight \\
\hline $\mathbf{1 3}$ & Rame of the medicine \\
\hline $\mathbf{1 4}$ & Strength of drug \\
\hline $\mathbf{1 5}$ & Dosage form \\
\hline $\mathbf{1 6}$ & Dosing instructions \\
\hline $\mathbf{1 7}$ & $\begin{array}{l}\text { Total quantity of medicine and duration of } \\
\text { medication }\end{array}$ \\
\hline $\mathbf{1 8}$ & Specific instructions if any \\
\hline $\mathbf{1 9}$ & Doctor's signature and date \\
\hline
\end{tabular}

\section{RESULTS}

The average score obtained for each student and the mean score calculated for both the study groups. The mean 
score for the five prescriptions obtained by the students in the group A (by 19-point score) was 15.90 and that of the group B was 13.14 (Figure 1).

On comparison of the mean score obtained by both the groups with Mann-Whitney U test, there was a significant difference between both the groups $(\mathrm{p}<0.001)$.

The performance of students in both the groups with regard to the individual parameters of the 19-point score was also assessed. The total of 185 prescriptions obtained from group A and 170 prescriptions obtained from group B were compared for the individual parameters by Chisquare test. There was a significant difference between groups in writing doctor's qualifications, registration no., contacts of prescriber, patient's full address, patient's weight, name of the medicine, strength of drug, dosage form, dosing instructions, total quantity of medicine and duration of medication, specific instructions, if any (Table 2).

Feedback from students about the various aspects of the learning activity using a Likert scale is shown in Table 3. The average rating of each item in the questionnaire ranged from 4.22 to 4.65 . The minimum average score was 4.22 for item 3, which stated thatpatient-based teaching provided a context that helped in retaining relevant information; a maximum mean score of 4.65 was obtained for item 4, which stated that patient-based teaching can help in developing communication skills.

Table 2: Comparison of individual prescription parameters on 19-point score.

\begin{tabular}{|c|c|c|c|c|}
\hline S. no. & Parameters & $\begin{array}{l}\text { Number of correct } \\
\text { response (Group B, n=34) }\end{array}$ & $\begin{array}{l}\text { Number of correct } \\
\text { response (Group } A, n=37)\end{array}$ & Significance \\
\hline 1 & Doctor's full name & 168 & 180 & Not significant \\
\hline 2 & Doctor's qualifications & 139 & 180 & $\mathrm{P}<0.001$ \\
\hline 3 & Registration no. & 148 & 180 & $\mathrm{P}<0.001$ \\
\hline 4 & Address of doctor & 165 & 175 & Not significant \\
\hline 5 & Contacts (of prescriber) & 1 & 104 & $\mathrm{P}<0.001$ \\
\hline 6 & Date of prescription & 167 & 180 & Not significant \\
\hline 7 & Patient's full name & 166 & 179 & Not significant \\
\hline 8 & Patient's full address & 142 & 132 & $\mathrm{P}<0.01$ \\
\hline 9 & Patient's sex & 166 & 178 & Not significant \\
\hline 10 & Patient's age & 143 & 163 & Not significant \\
\hline 11 & Patient's weight & 46 & 139 & $\mathrm{P}<0.001$ \\
\hline 12 & $\mathrm{Rx}$ - superscription & 165 & 176 & Not significant \\
\hline 13 & Name of the medicine & 130 & 166 & $\mathrm{P}<0.001$ \\
\hline 14 & Strength of drug & 44 & 107 & $\mathrm{P}<0.001$ \\
\hline 15 & Dosage form & 115 & 160 & $\mathrm{P}<0.001$ \\
\hline 16 & Dosing instructions & 64 & 128 & $\mathrm{P}<0.001$ \\
\hline 17 & $\begin{array}{l}\text { Total quantity of medicine } \\
\text { and duration of medication }\end{array}$ & 54 & 125 & $\mathrm{P}<0.001$ \\
\hline 18 & Specific instructions if any & 53 & 117 & $\mathrm{P}<0.001$ \\
\hline 19 & Doctor's signature \& date & 158 & 174 & Not significant \\
\hline
\end{tabular}

Table 3: Responses to questions with a 5-point Likert scale.

\begin{tabular}{|c|c|c|c|c|c|c|c|}
\hline S. no. & Questions & $\begin{array}{l}\text { Strongly } \\
\text { agree (5) }\end{array}$ & $\begin{array}{l}\text { Agree } \\
\text { (4) }\end{array}$ & $\begin{array}{l}\text { Neither agree } \\
\text { nor disagree (3) }\end{array}$ & $\begin{array}{l}\text { Disagree } \\
\text { (2) }\end{array}$ & $\begin{array}{l}\text { Strongly } \\
\text { disagree (1) }\end{array}$ & $\begin{array}{l}\text { Satisfaction } \\
\text { index }\end{array}$ \\
\hline 1 & $\begin{array}{l}\text { Patient-based teaching } \\
\text { improved my learning } \\
\text { skills }\end{array}$ & 18 & 18 & ( & 0 & 0 & 90 \\
\hline 2 & $\begin{array}{l}\text { Patient-based teaching is a } \\
\text { good tool of teaching and } \\
\text { learning }\end{array}$ & 17 & 19 & 1 & 0 & 0 & 89.44 \\
\hline 3 & $\begin{array}{l}\text { Patient-based teaching } \\
\text { provided a context that } \\
\text { helped me retaining } \\
\text { relevant information }\end{array}$ & 12 & 22 & 2 & 1 & 0 & 85.71 \\
\hline 4 & $\begin{array}{l}\text { Patient-based teaching can } \\
\text { help in developing } \\
\text { communication skills }\end{array}$ & 26 & 9 & 2 & 0 & 0 & 94.85 \\
\hline 5 & $\begin{array}{l}\text { This method should be } \\
\text { included in early years of } \\
\text { MBBS }\end{array}$ & 20 & 12 & 2 & 2 & 1 & 87.42 \\
\hline
\end{tabular}




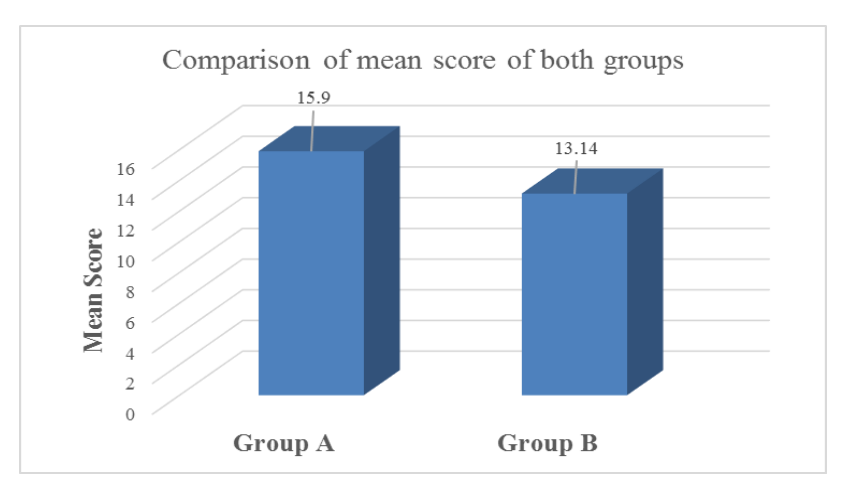

Figure 1: Comparison of mean score of both groups.

On evaluating the open-ended feedback from all students of group A, they concisely opined that patient-based teaching was interesting, helpful in developing communication skills, confidence and knowledge of clinical diagnosis. They also found it helpful in learning correlation of disease and treatment. They also suggested for more such sessions of patient-based teaching in pharmacology.

\section{DISCUSSION}

Prescription is a written order which is issued by the health professional to a patient. Prescription writing for common ailments is an important core competency of a medical undergraduate which involves a combination of knowledge, judgment and skills. As the poor prescribing lead to medication errors and related hazards each prescriber must be able to prescribe drugs safely and effectively to the designated patients in order to prevent medical errors. ${ }^{9}$

Case-based prescription training is included in the subject of pharmacology in the existing undergraduate medical curriculum. However, it is stated that case-based teaching would not be much effective for skills like prescribing, patient education and doing procedures. ${ }^{10}$ Therefore, there is a need for new educational interventions to improve prescribing.

Considering the above facts, the present study has been carried to check whether the patient-based teaching is useful in improving the prescribing skills in the second year MBBS students. The main findings of the present study are discussed below.

In our study the prescription writing skills of group A students who are trained by patient-based teaching is significantly better than group B who are trained in casebased teaching. Some of the studies have mentioned poor prescribing skills in fresh medical graduates. ${ }^{9}$ A Nigerian study emphasises on a more practice-based teaching of prescription writing as this study has reported mismatch between knowledge of drugs and prescribing skills among final year students. ${ }^{11}$
Analysis of the individual parameters of the 19-point score between both groups showed no significant difference in variables such as doctor's full name, address of doctor, date of prescription, patient's full name, patient's sex, patient's age, Rx superscription and doctor's signature and date. This shows that the students of group B were not able to memorize the drug information and reproduce it during prescription writing.

On other hand there was a significant difference noted between the groups in variables such as doctor's qualifications, registration no., contacts of prescriber, patient's full address, patient's weight, name of the medicine, strength of drug, dosage form, dosing instructions, total quantity of medicine and duration of medication and specific instructions, if any. Information regarding contacts of prescriber is important because it may be lifesaving if patient faces any adverse drug events. The lack of registration number may amount to a serious negligence on the part of the doctor. Standard prescription writing is not just writing the drugs and dose alone, every element in prescription is absolutely essential for both legal and therapeutic requirements. ${ }^{12}$

Above findings of our study confirms that the patientbased teaching improves the prescription writing skills of students compared to traditional case-based teaching.

Patient-based teaching method offers advantages to the students such as communication with patients, understanding their problems and empathy towards patients which help them to gain real life experience to enhance their memory and performance in prescribing writing. Feedback obtained from the students also brought out the fact that the patient-based teaching was interesting improves their learning skills, provides a context that helped them in retaining relevant information and in developing communication skills, confidence and knowledge of clinical diagnosis. They also found it helpful in learning correlation of disease and treatment and asked for more such sessions of patient-based teaching in pharmacology. Group A students also voted that the patient-based teaching is a good tool of teaching \&learning and therefore this method should be included in early years of MBBS. Our study results are in agreement with the study done by Thenrajan et al. ${ }^{13}$

Although we have not included the legible handwriting in our scoring system but it has been reported that illegible handwriting may lead to serious medication errors. ${ }^{14}$ Interestingly, in our study, handwriting of most participants was legible and comprehendible.

This study compares patient-based teaching with traditional case-based teaching in prescription writing skills of medical students. With this intervention of patient-based teaching, it can be assumed that students' prescription skills will be improved and they will be able to prescribe more effectively. Knowledge about students' perception regarding patient-based teaching is of great 
value for the regulatory or scientific body which designs or formulates the medical curriculum. Clinical pharmacologists should play an essential role in training of proper prescription writing skills among medical graduates. Prescription writing should be identified as an important core learning competency. It runs vertically through the medical curricula integrating with relevant horizontal modules. Patient-based teaching improves prescription writing skills of medical students and therefore it may fulfill need of new proper teaching module for prescription writing in order to prepare the students when they qualify to be doctors at the end of their final year. Difficulty in organization for a larger group of students, availability of adequate faculty and shorter duration of study are some of the limitations of the study.

\section{CONCLUSION}

Patient-based teaching improves the prescription writing skills of medical students in an effective way in comparison with traditional case-based teaching as the learning occurs within the context of real patients and is easier to recall. Therefore, patient-based teaching should be used widely as it offers lifelike preparation and has more relevance as a future doctor.

\section{ACKNOWLEDGEMENTS}

We are thankful to the Dean, M.P. Shah Govt. Medical College, Jamnagar and HOD of medicine, Guru Gobindsingh Government Hospital, Jamnagar for granting permission to carry out the study as well as all staff members of pharmacology department and all participants of study for their cooperation and support during study. We are also thankful to Medical Education Unit, Pramukh Swami Medical College, Karamsad for their guidance and motivation.

Funding: No funding sources Conflict of interest: None declared

Ethical approval: The study was approved by the Institutional Ethics Committee, M.P. Shah Govt. Medical College, Jamnagar

\section{REFERENCES}

1. Panchbhai AS. Rationality of prescription writing. Indian J Pharm Educ. 2013;47(4):7-15.

2. Aronson JK. A prescription for better prescribing. $\mathrm{Br}$ J Clin Pharmacol. 2006;61:487-91.

3. Calligaris L, Panzera A, Arnoldo L, Londero C, Quattrin R, Troncon MG, et al. Errors and omissions in hospital prescriptions: A survey of prescription writing in a hospital. BMC Pharmacol Toxicol. 2009;9:9.

4. Garbutt JM, Highstein G, Jeffe DB, Dunagan WC, Fraser VJ. Safe medication prescribing: Training and experience of medical students and house staff at a large teaching hospital. Acad Med. 2005;80:594-9.

5. Han WH, Maxwell SR. Are medical students adequately trained to prescribe at the point of graduation? Views of first year foundation doctors. Scott Med J. 2006;51:27-32.

6. Dammers J, Spencer J, Thomas M. Using real patients in problem-based learning: Students' comments on the value of using real, as opposed to paper cases, in a problem-based learning module in general practice. Med Educ. 2001;35:27-34.

7. Maharashtra model medicine prescription format. Available at: https://fda.maharashtra.gov.in/ downloads/fda\%2027feb2014\%20final.pdf. Accessed on 2 January 2019.

8. Bhandari B, Mehta B, Mavai M, Singh YR, Singhal A. Jigsaw Method: An Innovative way of cooperative learning in physiology. Indian J Physiol Pharmacol. 2017;61:315-21.

9. Likic R, Maxwell SR. Prevention of medication errors: Teaching and training. Br J Clin Pharmacol. 2009;67:656-61.

10. Koh GC, Khoo HE, Wong ML, Koh D. The effects of problem-based learning during medical school on physician competency: A systemic review. CMAJ. 2008; 178:34-41.

11. Oshikoya KA, BelloJa A, Ayorinde EO. Prescribing knowledge and skills of final year medical students in Nigeria. Indian J Pharmacol. 2008;40:251-5.

12. Mohammad IS, Khan HM, Akhtar N, Saqib NU, Rasool F, Ijas H. Significance of prescription elements and reasons of prescription errors in South Panjab, Pakistan. World Appl Sci J. 2015;33:668-72.

13. Thenrajan P, Murugan PR. Impact of patient-based teaching in improving prescription writing skills of II MBBS students. Int J Appl Basic Med Res. 2016;6:174-7.

14. Hester DO. Do you see what I see? Illegible handwriting can cause patient injuries. J Ky Med Assoc. 2001;99(5):187.

Cite this article as: Jadav SP, Bhansali NB, Parmar DM. Comparative study of patient-based versus casebased teaching in prescription writing skills of second year MBBS students. Int J Basic Clin Pharmacol 2020;9:289-95. 


\section{ANNEXURE}

\section{Questionnaire}

Questionnaire to measure perception of undergraduate medical students about patient-based teaching method Name (Optional): Age (Years): Gender:

- $\quad$ Please tick the appropriate option for question number 1 to 5.

- Give your free opinion for question number 6 to 8 .

1. Patient-based teaching improved my learning skills.
a) Strongly agree
b) Agree
c) Neither agree nor disagree
d) Disagree
e) Strongly disagree

2. Patient-based teaching is a good tool of teaching and learning.
a) Strongly agree
b) Agree
c) Neither agree nor disagree
d) Disagree
e) Strongly disagree

3. Patient-based teaching provided a context that helped me retaining relevant information.
a) Strongly agree
b) Agree
c) Neither agree nor disagree
d) Disagree
e) Strongly disagree on

4. Patient-based teaching can help in developing communication skills.
a) Strongly agree
b) Agree
c) Neither agree nor disagree
d) Disagree
e) Strongly disagree

5. This method should be included in early years of MBBS.
a) Strongly agree
b) Agree
c) Neither agree nor disagree
d) Disagree
e) Strongly disagree

6. What is your opinion about patient-based teaching method? 
7. Which modification you suggest for better teaching learning?

8. Which part of pharmacology should be focused more? 